\title{
Morfo-anatomia comparada das folhas do par vicariante Plathymenia foliolosa Benth. e Plathymenia reticulata Benth. (Leguminosae - Mimosoideae)
}

\author{
IRENE DA COSTA A. MENDES ${ }^{1}$ e THEREZINHA ISAIA PAVIANI ${ }^{1}$
}

(recebido em 20/12/95; aceito em 04/03/97)

\begin{abstract}
Comparative morpho-anatomy of leaves from the vicariant pair Plathymenia foliolosa Benth. and Plathymenia reticulata Benth. (Leguminosae-Mimosoideae)). The bipinnate adult leaves of $P$. foliolosa from the forest (Minas Gerais) and $P$. reticulata from the cerrado vegetation of Brasília (DF), Brazil, were studied. All parts of the leaves were examined under the light microscope with normal and polarized light. P. reticulata leaflets are larger than those of $P$. foliolosa. The anatomical structure in all parts shows subtle differences which may be of ecological importance. The stomata occur either at the same level as the adjacent epidermal cells or they may be slightly sunken in P. reticulata or slightly raised in P. foliolosa. The leaflet blade is wider in $P$. reticulata and the mesophyll cells are more tightly arranged. The leaflet blade is hypostomatic, dorsiventral with two layers of palisade parenchyma in $P$. reticulata and one layer in $P$. foliolosa. The cutinization process is more intense in the epidermal cell walls of $P$. reticulata. Calcium oxalate crystals are more abundant in $P$. foliolosa although crystal redissolution was seen in both species. Stronger scleromorphism (from the anatomical point of view), greater amount of phenolic deposits and gelatinous fibers are features more conspicuous in P. reticulata. The similar structural organization recorded for the two vicariant species agrees with their close taxonomic relationship and the differential anatomical features may be related to the environmental factors of the species' habitat.

RESUMO - (Morfo-anatomia comparada das folhas do par vicariante Plathymenia foliolosa Benth. e Plathymenia reticulata Benth. (Leguminosae-Mimosoideae)). Folhas bipinadas adultas de P. foliolosa e P. reticulata da mata (Minas Gerais) e do cerrado (Distrito Federal) respectivamente, foram estudadas, sob o ponto de vista comparativo, quanto à morfologia externa e à anatomia. Todas as partes foliares foram examinadas sob microscopia óptica, em luz normal e em luz polarizada. Os folíolos de $P$. reticulata são maiores que os de $P$. foliolosa. A organização do sistema vascular é semelhante nas duas espécies. Em $P$. reticulata, os estômatos estão no mesmo nível ou levemente depressionados em relação às demais células epidérmicas e, em P. foliolosa, estas estruturas mostram posição ligeiramente elevada. A lâmina foliolar é mais espessa e o mesofilo é mais compacto em $P$. reticulata. As lâminas foliolares são hipoestomáticas e dorsiventrais com dois estratos de parênquima paliçádico em $P$. reticulata e um estrato em $P$. foliolosa. A cutinização é mais intensa nas paredes das células epidérmicas de $P$. reticulata. Cristais de oxalato de cálcio são mais abundantes em $P$. foliolosa embora a redissolução dos mesmos tenha sido observada, para ambas as espécies, sobretudo no pulvino primário. O escleromorfismo, encarado sob o ponto de vista anatômico, é mais acentuado em $P$. reticulata e, nesta espécie, a quantidade de taninos e de fibras gelatinosas também é maior. A semelhança constatada na organização estrutural como um todo é condizente com a proximidade taxonômica das duas espécies e os aspectos anatômicos diferenciais sugerem estar relacionados com o habitat de $P$. foliolosa e $P$. reticulata.
\end{abstract}

Key words - Plathymenia, ecological anatomy, leaves, vicariance

\section{Introdução}

As espécies vicariantes são muito próximas taxonomicamente, apresentam estreito grau de parentesco e os aspectos morfológicos que as distinguem podem ser resultantes da diversidade do ambiente.

A pesquisa em morfo-anatomia comparada de espécies vicariantes sugere a formulação de hipótese que seguem, principalmente, quatro raciocínios: algumas diferenças na morfologia externa são percetíveis, embora permaneça resguardada a semelhança dos fenótipos; as diferenças anatômicas são sutis e percebidas por meio de observações acuradas, o que estabelece um

1. Departamento de Botânica, Instituto de Ciências Biológicas. Universidade de Brasília, Caixa Postal 04631, 70919-970 Brasília, DF, Brasil. equilíbrio entre o paralelismo taxonômico das espécies e a influência do habitat; as diferenças anatômicas são significativas e a influência do ambiente é marcante; não se observam particularidades anatômicas diferenciais, predominando a afinidade taxonômica dos pares.

O estudo morfo-anatômico comparado de espécies vicariantes contribui, consideravelmente, para carrear subsídios à anatomia ecológica. A folha é um órgão que, dadas as características de forma e função que lhe conferem plasticidade, adapta-se facilmente ao ambiente no qual vive e, assim sendo, é indicada para estudos desta natureza.

Este trabalho objetiva detectar as semelhanças $\mathrm{e}$ as diferenças que ocorrem entre as folhas bipinadas de Plathymenia foliolosa Benth. (vinhático-damata) e $P$. reticulata Benth. (vinhático-do-campo), par vicariante, a primeira das florestas pluviais e a segunda, do cerrado (Rizzini 1971), 
contribuindo para o maior conhecimento da vicariância e das peculiaridades morfo-anatômicas resultantes da influência do habitat.

\section{Material e métodos}

Folhas adultas de Plathymenia foliolosa foram coletadas de indivíduos procedentes da Estação Florestal de Experimentação (EFLEX), do IBAMA, em Paraopeba, MG. As folhas de $P$. reticulata foram coletadas de indivíduos que ocorrem no campus da Universidade de Brasília (UnB), área de cerrado, próxima ao Centro Olímpico, DF.

Exsicatas do material botânico foram depositadas no Herbário da Universidade de Brasília (UB), com as seguintes indicações Plathymenia foliolosa Benth. col.: Irene da Costa A. Mendes, no 74 e no 120 e Plathymenia reticulata Benth. col.: Irene da Costa A. Mendes, no 124, no 125 e no 177.

Terços médios do pulvino primário, pecíolo, raque, pulvino secundário, peciólulo, raquila, pulvino terciário e folíolos foram fixados em FAA $50^{\circ} \mathrm{GL}$ e, posteriormente, submetidos a cortes histológicos, à mão livre e em micrótomo rotatório AO Spencer-820, após desidratação em série etílica e inclusão em parafina (Johansen 1940, Sass 1958). Foi utilizada a dupla coloração safranina-"fast-green" e, como meio de montagem, o entellan. O material foi observado em microscopia óptica (luz normal e polarizada).

As observações e desenhos das epidermes adaxial e abaxial, em vista de face, foram feitos a partir de cortes paradérmicos à mão livre com o auxílio de gilete.

Para o estudo da venação, os folíolos foram clarificados pelo processo de Foster (1949), desidratados, corados em safranina e montados permanentemente.

Medidas de espessura da lâmina foliolar, da parede periclinal externa das células das epidermes adaxial e abaxial e do bordo dos folíolos, em número de 25 aferições para cada medida, foram feitas com nônio ocular e calculadas pelo fator correspondente. A parece periclinal externa foi medida em cortes à mão livre, de material fixado, tratados pelo sudan IV, que permite evidenciar a cutinização (Johansen 1940). Como a parede periclinal externa das células epidérmicas é totalmente cutinizada, não foi possível distinguir a cutícula, razão porque optou-se pela medida da espessura de toda a parede. $\mathrm{O}$ número de estômatos presentes na epiderme abaxial foi obtido projetando-se, no papel, em quadrado de $0,5 \mathrm{~mm}$ de lado. A soma da contagem em quatro áreas contíguas representou o número de estômatos presentes em 1 $\mathrm{mm}^{2}$. Foram feitas 100 contagens, obtendo-se uma amostragem de $n=25$. Para as medidas e para o número de estômatos foram calculados a média aritmética, o desvio padrão e o intervalo de confiança. Para as medidas, o intervalo de confiança foi calculado para a média populacional com variância desconhecida, construído com valores da tabela $T$ de Student e, para o número de estômatos, foram usados os valores da distribuição normal padrão.

O tanino foi visualizado pelo cloreto férrico (Johansen 1940), e as paredes lignificadas pela floroglucina sulfúrica a $25 \%$ (modificada de Paula 1971) e pela floroglucina clorídrica a $25 \%$ (Johansen 1940).

A natureza química dos cristais foi constatada pela mistura modificada de Wasicky (1959), de ácido sulfúrico a $25 \%$, álcool etílico $70^{\circ}$ GL e hidrato de cloral a $60 \%$, na proporção de 3:5:2 volumes, respectivamente, utilizando-se material fixado; os cortes à mão livre foram observados antes e depois da aplicação de gotas da mistura.

Os desenhos e diagramas foram executados com o auxílio de câmara clara com "zoom", adaptada em microscópio Carl Zeiss modelo Axioscop e em estereomicroscópio Zeiss. As fotomicrografias foram obtidas em fotomicroscópio Carl Zeiss-I.

\section{Resultados}

Em ambas as espécies, as folhas são bipinadas (figura 1). Os folíolos são elíptico-ovalados, emarginados e a venação é do tipo broquidódromo, sendo que o folíolo de Plathymenia reticulata é maior (figura 2) que o de P. foliolosa (figura 3).

Comparando-se as duas espécies, a diferença na espessura da lâmina foliolar, no terço médio, é significativa (tabela 1); a diferença na espessura da parede periclinal externa das células epidérmicas é significativa para a epiderme abaxial, não sendo significativa para a epiderme adaxial e para o bordo (tabela 2). Na lâmina foliolar das duas espécies, os dados médios mostram que a parede periclinal

Tabela 1. Medida (em $\mu \mathrm{m})$ da espessura da lâmina foliolar de espécies de Plathymenia $(\mathrm{n}=25)$ : mínima, máxima e média aritmética $(\overline{\mathrm{x}})$, seguidas de desvio padrão (s) e intervalo de confiança (IC).

\begin{tabular}{cccccc}
\hline Espécies & Mínima & Máxima & $\overline{\mathrm{x}}$ & $\mathrm{s}$ & $\mathrm{IC}_{95 \%}$ \\
\hline P. foliolosa & 122,84 & 173,50 & 141,41 & 13,96 & $135,65-147,17$ \\
$P$. reticulata & 156,25 & 212,50 & 179,66 & 14,75 & $173,57-185,75$ \\
\hline
\end{tabular}

Tabela 2. Medida (em $\mu \mathrm{m}$ ) da espessura da parede periclinal externa das células epidérmicas de espécies de Plathymenia (n=25): mínima (Min.), máxima (Máx.) e média aritmética ( $\bar{x})$, seguidas de desvio padrão (s) e intervalo de confiança (IC).

\begin{tabular}{|c|c|c|c|c|c|c|c|c|c|c|c|c|c|c|c|}
\hline \multirow[t]{2}{*}{ Espécies } & \multicolumn{8}{|c|}{ Epiderme adaxial } & \multicolumn{3}{|c|}{ Epiderme abaxial } & \multicolumn{4}{|c|}{ Bordo } \\
\hline & Min. & Máx. & $\overline{\mathrm{X}}$ & $\mathrm{s}$ & $\mathrm{IC}_{95 \%}$ & Min. & Máx. & $\overline{\mathrm{x}}$ & $\mathrm{s}$ & $\mathrm{IC}_{95 \%}$ & Min. & Máx. & $\overline{\mathrm{x}}$ & $\mathrm{s}$ & $\mathrm{IC}_{95 \%}$ \\
\hline P. foliolosa & 3,42 & 6,85 & 5,13 & 0,98 & $(4,73-5,53)$ & 0,96 & 1,82 & 1,48 & 0,26 & $(1,37-1,59)$ & 3,64 & 7,17 & 5,51 & 0,76 & $(5,20-5,82)$ \\
\hline P. reticulata & 3,53 & 7,06 & 5,26 & 0,82 & $(4,92-5,60)$ & 0,96 & 2,02 & 1,24 & 0,28 & $(1,12-1,36)$ & 3,53 & 7,17 & 5,09 & 0,96 & $(4,69-5,49)$ \\
\hline
\end{tabular}




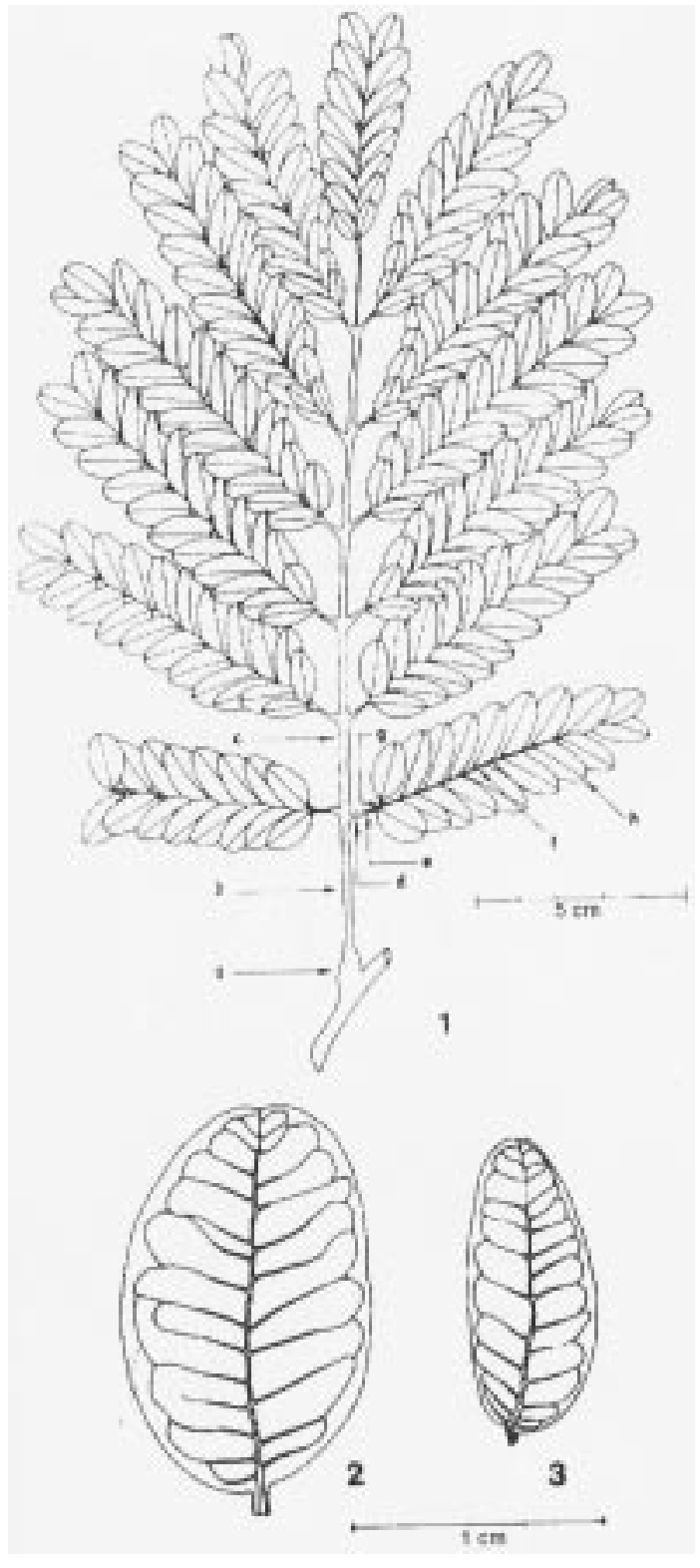

Figuras 1-3. Folha e folíolos. 1. Folha duplamente composta de Plathymenia reticulata: a. pulvino primário; b. pecíolo; c. raque; d. pulvino secundário; e. peciólulo; f. raquila; g. pulvino terciário; h. folíolo. 2-3. Folíolo. 2. P. reticulata; 3. P. foliolosa. externa das células da epiderme adaxial e do bordo é três ou quatro vezes mais espessa do que a parede periclinal externa das células da epiderme abaxial (tabela 2). A reação com sudan IV evidenciou cutinização mais intensa em $P$. reticulata, tanto nas paredes periclinais como nas anticlinais. Em $P$. foliolosa, geralmente, não se observa cutinização nas paredes periclinal interna e anticlinais.

A lâmina foliolar, dorsiventral e hipoestomática, possui epiderme unisseriada e as paredes anticlinais das células das epidermes adaxial e abaxial do folíolo são sinuosas em $P$. foliolosa (figuras 4 e 5) e retas em $P$. reticulata (figuras 6 e 7). Os estômatos são anomocíticos ou paracíticos em ambas as espécies (figuras 5 e 7) e em $P$. reticulata posicionam-se no nível das demais células epidérmicas ou estão ligeiramente depressionados (figura 8); em $P$. foliolosa, os estômatos estão levemente elevados em relação às outras células da epiderme (figuras 9 e 13). Os estômatos são mais numerosos em $P$. foliolosa $\left(\overline{\mathrm{x}}=307 / \mathrm{mm}^{2}\right)$ do que em $P$. reticulata $\left(\overline{\mathrm{x}}=205 / \mathrm{mm}^{2}\right)$, sendo que esta diferença é significativa (tabela 3 ).

O feixe vascular da nervura principal dispõe-se em semicírculo e é mais desenvolvido em $P$. reticulata. O feixe vascular é cercado por fibras gelatinosas vistas nos lados adaxial e abaxial. Abaixo das duas epidermes há idioblastos cristalíferos; os cristais são de oxalato de cálcio e de forma romboédrica. Na nervura principal e no mesofilo os cristais são mais abundantes em P. foliolosa, sendo raros em $P$. reticulata.

O mesofilo é mais desenvolvido e mais compactado em $P$. reticulata. Os parênquima paliçádico esboça dois ou três estratos celulares em $P$. reticulata (figura 10), enquanto que em $P$. foliolosa, um ou dois, predominando um estrato de células (figura 11). A altura das células em paliçada é ligeiramente maior em $P$. reticulata (figura 10). Os feixes vasculares menores do mesofilo são cercados por bainha parenquimática e os maiores possuem extensão de bainha que alcança as duas epidermes,

Tabela 3. Número de estômatos (por $\left.\mathrm{mm}^{2}\right)$ na epiderme abaxial de espécies de Plathymenia $(\mathrm{n}=25)$ : mínimo, máximo e média aritmética $(\overline{\mathrm{x}})$, seguidos de desvio padrão (s) e intervalo de confiança (IC).

\begin{tabular}{cccccc}
\hline Espécies & Mínimo & Máximo & $\overline{\mathrm{x}}$ & $\mathrm{s}$ & $\mathrm{IC}_{95 \%}$ \\
\hline P. foliolosa & 256 & 359 & 307 & 20,54 & $(298,95-315,05)$ \\
P. reticulata & 153 & 253 & 205 & 26,21 & $(194,73-215,27)$ \\
\hline
\end{tabular}


sendo que em $P$. reticulata a extensão de bainha para a epiderme abaxial é constituída por um maior números de células (figura 12), se comparada à $P$. foliolosa (figura 13). Fibras e cristais romboédricos de oxalato de cálcio acompanham os feixes vasculares maiores; as fibras são em maior número no lado abaxial. O bordo foliolar das duas espécies mostra colênquima anelar, com maior número de

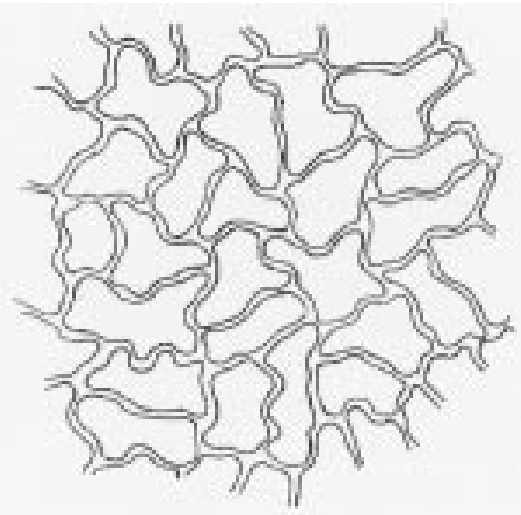

4
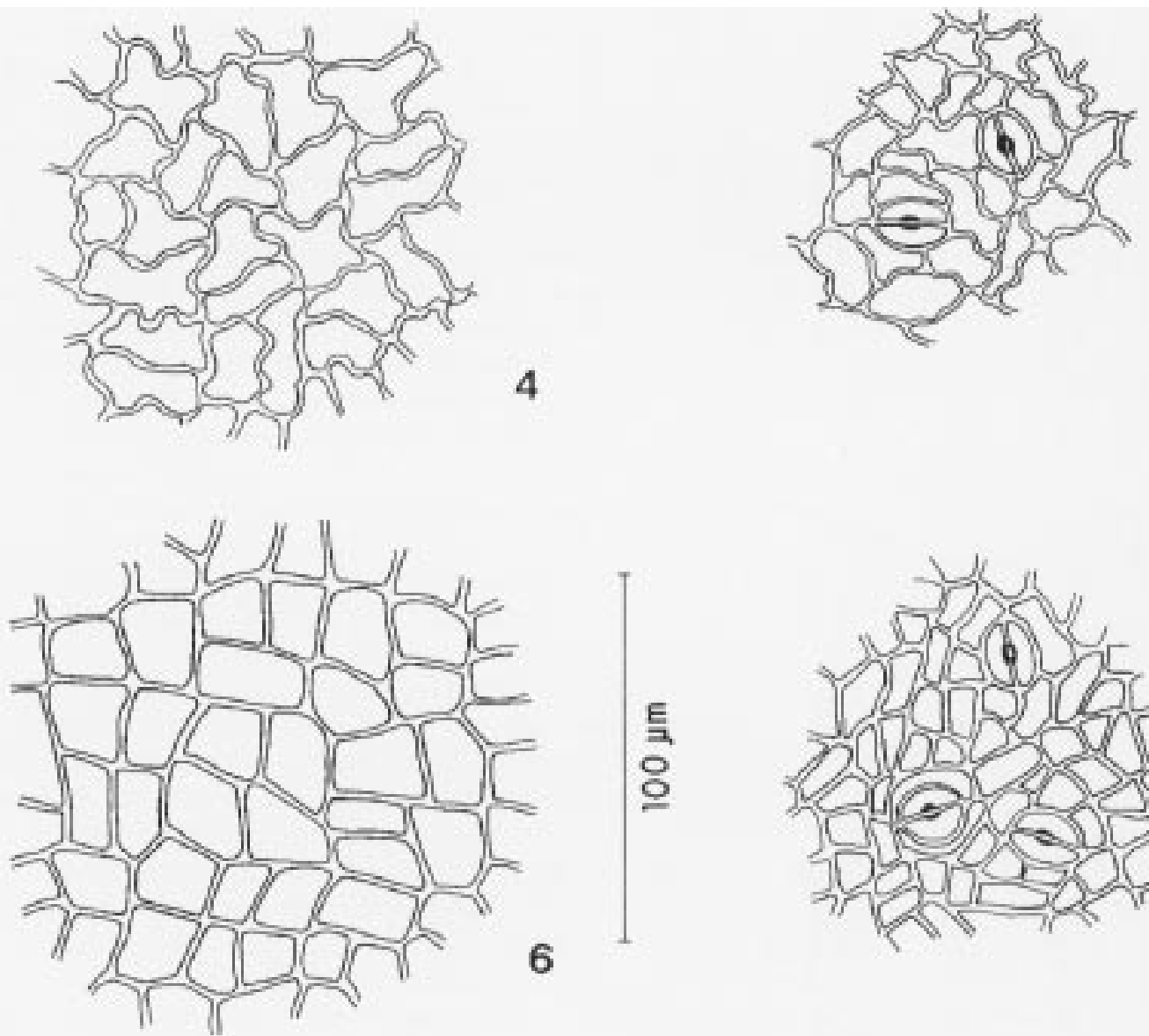

6
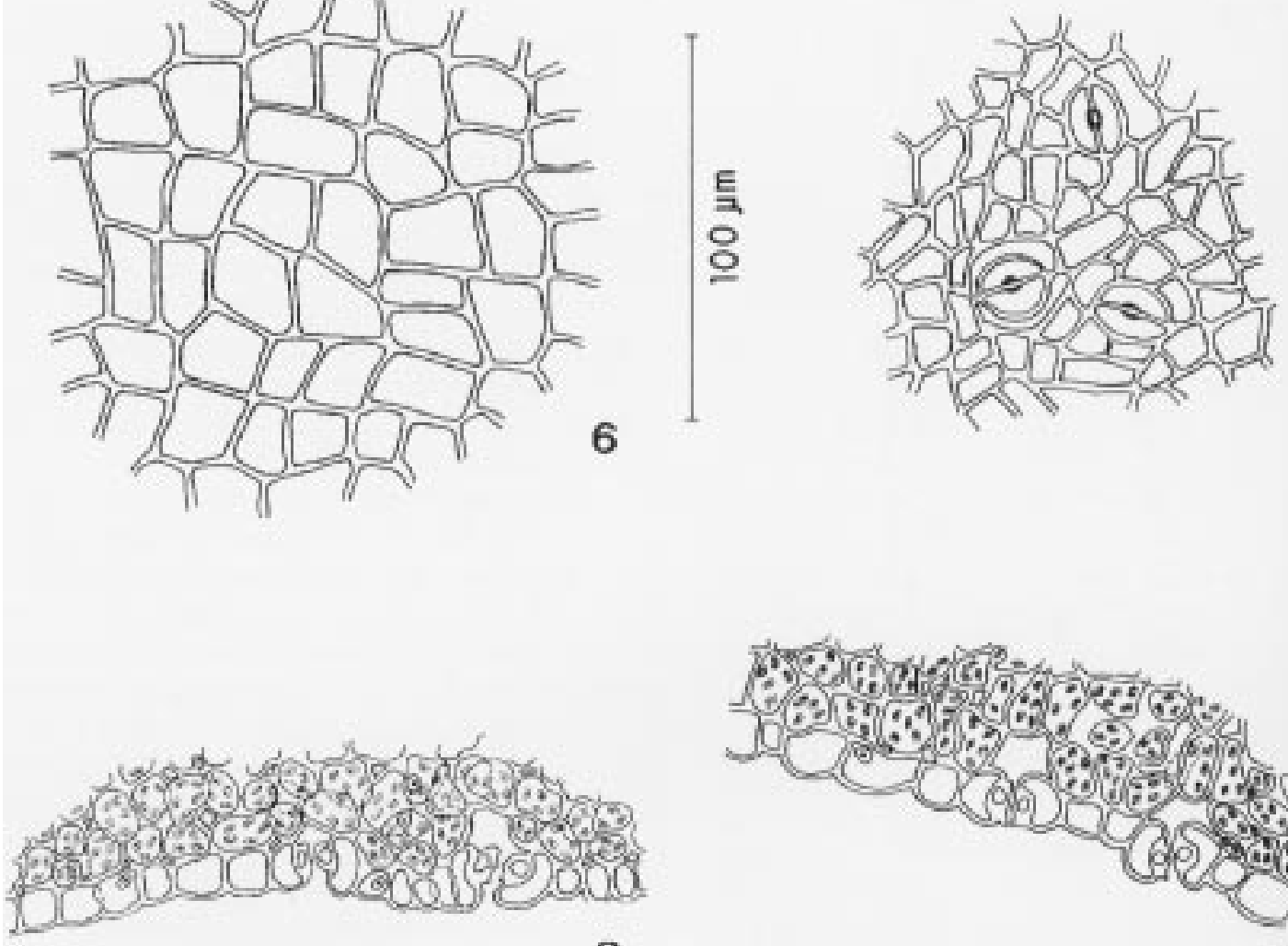

8

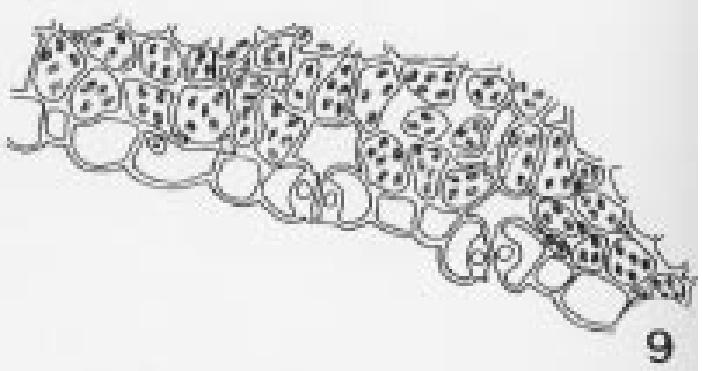

Figuras 4-9. Lâmina foliolar. 4-5. Plathymenia foliolosa. 4. Epiderme adaxial. 5. Epiderme abaxial. 6-7. P. reticulata. 6. Epiderme adaxial; 7. Epiderme abaxial. 8-9. Corte transversal da epiderme abaxial; estômatos. 8. P. reticulata, 9. P. foliolosa. 
estratos em $P$. reticulata (figuras 14 e 15). Tanino como conteúdo ocorre nas células do mesofilo e é encontrado em maior quantidade em $P$. reticulata.

A organização tissular do pulvino primário, pecíolo, raque, pulvino secundário, peciólulo, raquila, pulvino terciário e folíolo, ilustrada para $P$. foliolosa (figuras 16 a 23A) é semelhante em ambas as espécies. Em P. foliolosa todas as partes foliares são menos desenvolvidas do que em $P$. reticulata. A cutinização das células epidérmicas é mais intensa em $P$. reticulata. No pulvino primário, pecíolo e raque de $P$. reticulata, a cutinização atinge as paredes anticlinais, total ou parcialmente e, no pulvino primário, algumas paredes periclinais internas também são cutinizadas.

O córtex é colenquimatoso e parenquimatoso no pecíolo, raque, peciólulo e raquila e parenquimatoso nos pulvinos primário, secundário e terciário, para ambas as espécies. O colênquima é angular, descontínuo e irregular quanto à posição. Tanino ocorre com freqüência nas células do córtex, é encontrado em maior quantidade no lado adaxial das partes foliares e é mais abundante, de um modo geral, em $P$. reticulata (figura 24) e menos abundante em $P$. foliolosa (figura 25). No córtex há cristais romboédricos de oxalato de cálcio (figura 26) os quais, após a aplicação do teste, tomam forma de bastões alongados (figura 27). O mesmo ocorre para os cristais das demais partes foliares.

No córtex os cristais são mais abundantes em P. foliolosa; são encontrados no pulvino primário, pecíolo, raque, pulvino secundário e peciólulo (figuras 28 e 29); são menos freqüentes nas partes mais externas do córtex o que é mais notado no pulvino primário e raros no pulvino terciário e na raquila. Em $P$. reticulata, a localização dos cristais é a mesma, porém, a quantidade diminui consideravelmente, sendo mais freqüentes no pulvino primário (figura 29). Nas duas espécies observa-se o fenômeno da redissolução dos cristais, acompanhado do processo de lignificação das paredes das células que contêm o cristal, o que é visto sobretudo no pulvino primário (figura 26), pecíolo e pulvino secundário. A lignificação destas paredes foi melhor evidenciada com a floroglucina sulfúrica a $25 \%$.

A região perivascular possui células com paredes espessadas, não lignificadas, de aspecto colenquimatoso nos pulvinos primário, secundário e terciário (figuras 16,19 e 22) e é esclerenquimática no pecíolo, raque, peciólulo e raquila (figuras 17,18 , 20 e 21), em ambas as espécies. O esclerênquima é constituído por fibras, sendo que em $P$. reticulata, além das fibras, ocorrem alguns esclereídeos no pecíolo e na raque e poucos na raquila. No pecíolo, peciólulo e raque de $P$. foliolosa e de $P$. reticulata as fibras perivasculares são do tipo gelatinosas (figuras 30 e 31). Em P. reticulata, as fibras gelatinosas são vistas também na raquila e em $P$. foliolosa esses elementos são escassos no peciólulo e não foram vistos na raquila. A presença das fibras gelatinosas é mais acentuada no lado adaxial das partes foliares. O teste com floroglucina clorídrica evidenciou a lignificação apenas da parte mais externa da parede celular; a dupla coloração safranina-"fastgreen" corou em vermelho a porção lignificada da parede e em verde, a camada gelatinosa. A observação em luz polarizada mostrou a condição isotrópica da camada gelatinosa.

O teste com floroglucina clorídrica, a observação em luz polarizada e a dupla coloração safranina"fast-green" tornaram muito nítido o fato que, em $P$. reticulata, a presença das fibras gelatinosas é mais notada principalmente no que se refere a maior quantidade desses elementos e a maior espessura da camada gelatinosa (figura 30), se comparadas com as de $P$. foliolosa (figura 31). As fibras homogêneas, sobretudo as do xilema, também são mais abundantes em $P$. reticulata.

Em todos os componentes da folha composta, o arranjo do sistema vascular é semelhante para as duas espécies. Os tecidos vasculares estão dispostos em dois conjuntos, um externo distribuído em anel e outro interno que pode ser subdividido em vários feixes vasculares (de número variável, conforme o nível de corte), tendo o floema dos dois lados do xilema (figuras 16 a 21). Pequenas variações neste arranjo são vistas no pulvino secundário (figura 19), peciólulo (figura 20) e raquila. Nesta última, no lado adaxial, destaca-se um feixe vascular, concêntrico e anficrival, cercado por fibras (figura 21).

Fibras gelatinosas estão presentes no xilema do pulvino primário, pecíolo, raque, pulvino secundário e peciólulo de P. reticulata. Em P. foliolosa, observam-se algumas fibras gelatinosas no xilema do pecíolo. No sistema vascular do pulvino primário, pecíolo, raque, peciólulo e raquila de $P$. reticulata 

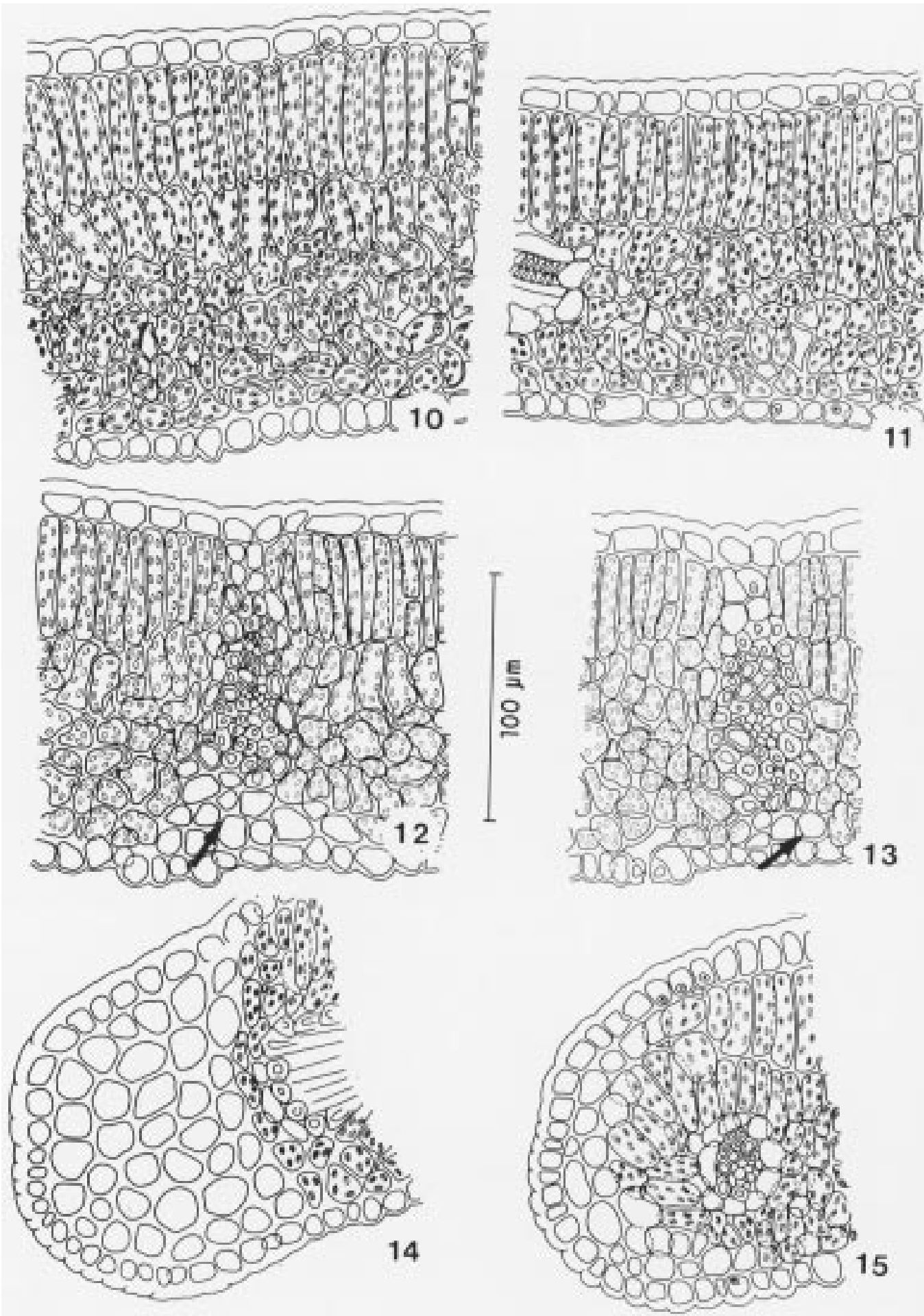

Figuras 10-15. Cortes transversais da lâmina foliolar. 10, 12, 14. Plathymenia reticulata. 11, 13, 15. P. foliolosa. 10-11. Mesofilo; 12-13. Feixes vasculares com extensões de bainha (as setas indicam as extensões de bainha para o lado abaxial); $14-$ 15. Bordos Colênquima mais desenvolvido em P. reticulata. 

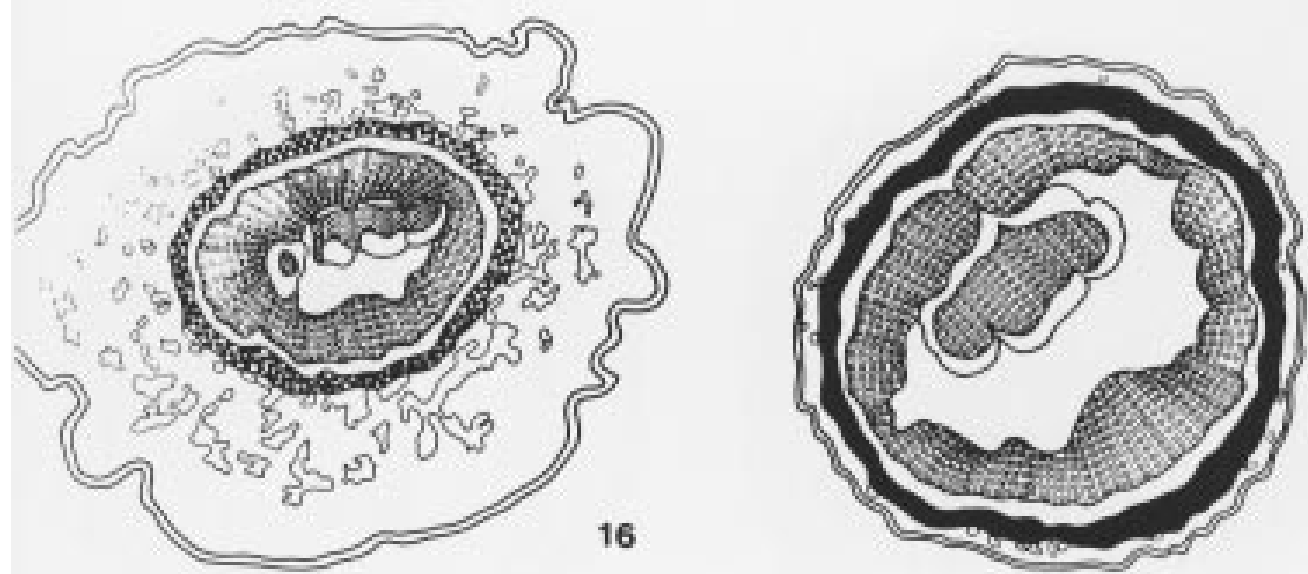

17
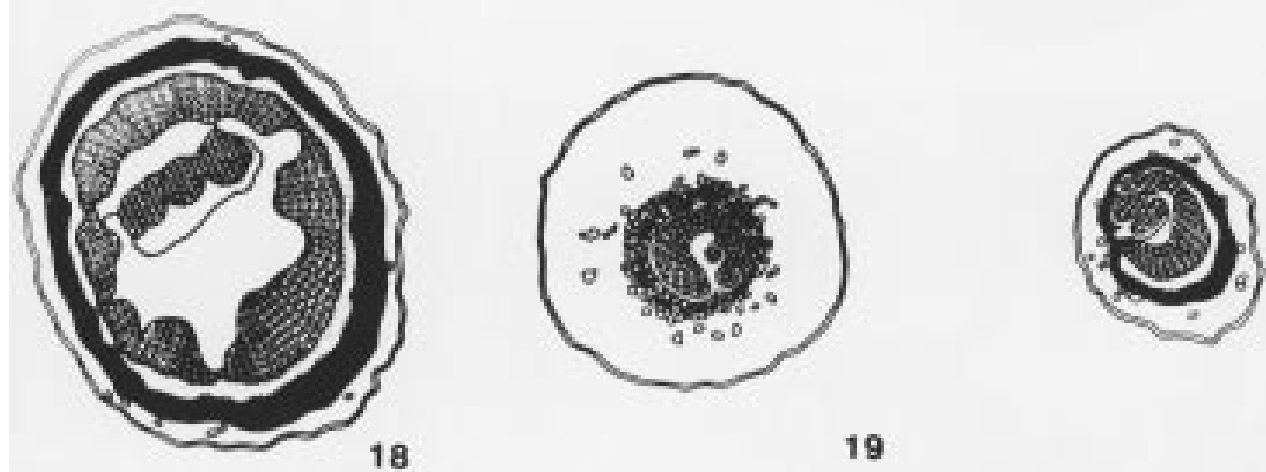

18

19

20
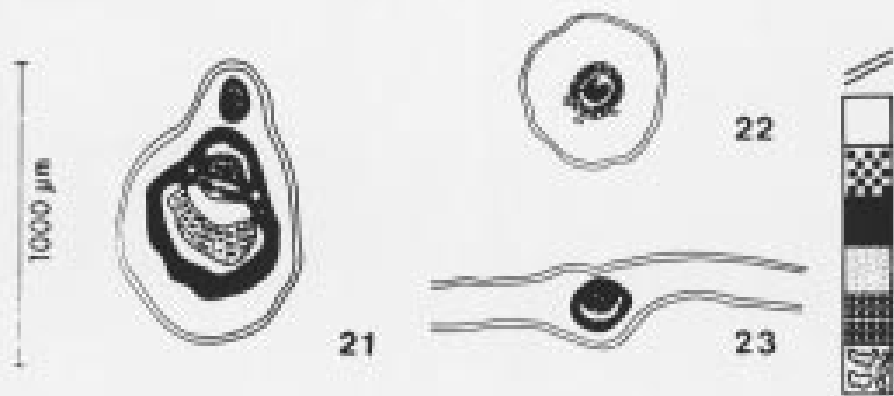

Epideres

Parkequiat su partaeaiat o selasquine

Regies con chlalas de peredes espossados

Esciorkaquied

floeses

21

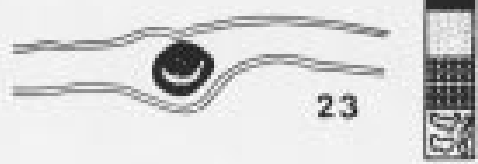

Xileas

Coleles cantende cristeis

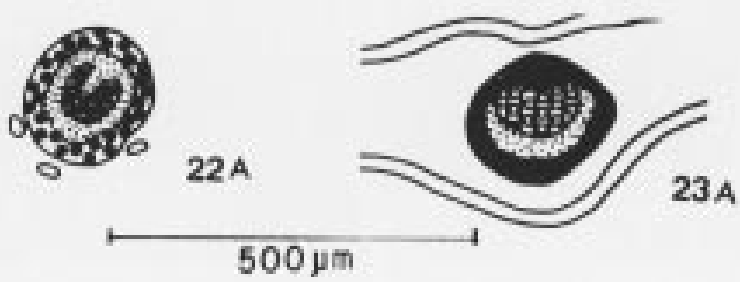

Figuras 16-23. Cortes transversais das partes da folha bipinada de Plathymenia foliolosa. 16. Pulvino primário. 17. Pecíolo; 18. Raque; 19. Pulvino secundário; 20. Peciólulo; 21. Raquila; 22. Pulvino terciário; 22A. Detalhe da organização dos tecidos do pulvino terciário; 23. Nervura principal da lâmina foliolar; 23A. Detalhe da organização dos tecidos da nervura principal. 


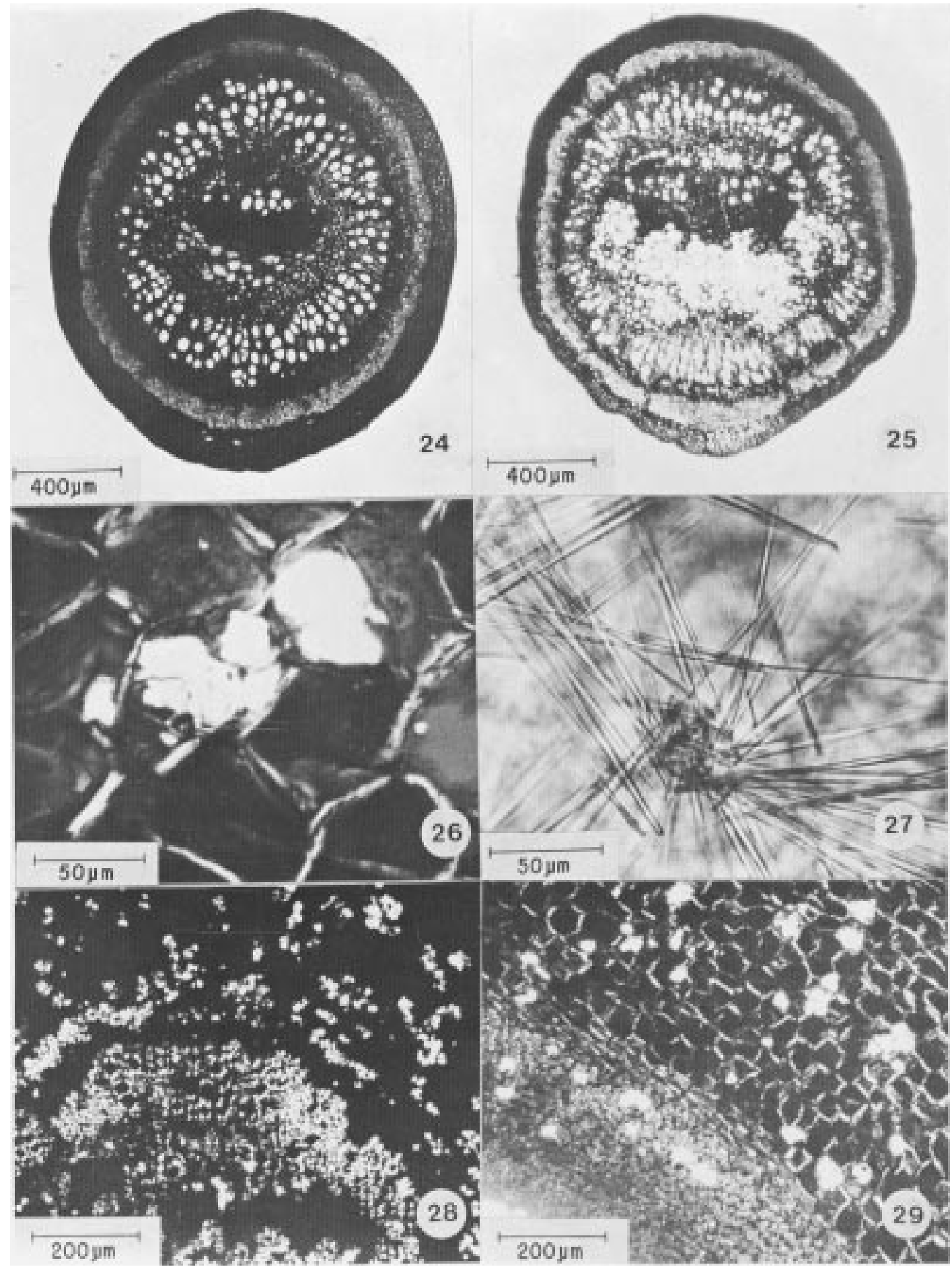

Figuras 24-29. Cortes transversais da raque e do pulvino primário. 24-25. Teste para tanino na raque. 24. Plathymenia reticulata; 25. P. foliolosa. 26-27. Pulvino primário de P. reticulata. 26. Cristais de oxalato de cálcio, antes do teste microquímico; luz polarizada; 27. Aspecto dos cristais após o teste microquímico. 28-29. Cristais no córtex e no floema (luz polarizada) do pulvino primário. 28. P. foliolosa; 29. P. reticulata. 
não foram encontrados cristais. No pulvino primário de $P$. foliolosa os cristais estão presentes no parênquima do floema e no pecíolo; na raque e no peciólulo ocorrem no protoxilema e no floema. Em ambas as espécies, nas células parenquimáticas do floema, há tanino como conteúdo no pulvino primário, pecíolo, raqui, pulvino secundário, peciólulo e raquila; este conteúdo é mais abundante em $P$. reticulata (figura 24 ).

Em $P$. foliolosa, a medula, situada em posição excêntrica, é mais evidente no pulvino primário, no pecíolo, na raque e na raquila (figuras 16, 17, $18 \mathrm{e}$ 21), rudimentar no peciólulo (figura 20) e ausente, nos pulvinos secundário e terciário (Figuras 19 e 22). Na medula do pulvino de $P$. foliolosa ocorrem cristais romboédricos de oxalato de cálcio. Em $P$. reticulata, a medula é mais desenvolvida no pecíolo e na raque, rudimentar no pulvino primário, peciólulo e raquila e está ausente nos pulvinos secundário e terciário.

\section{Discussão}

Segundo Esau (1977), plantas que se desenvolvem sob luz solar intensa geralmente possuem folhas menores; isto não se aplica à $P$. reticulata que possui folíolo maior em comparação ao de $P$. foliolosa. Convém lembrar que os caracteres adaptativos não podem ser generalizados e que os mesmos variam entre as plantas de um mesmo ecossistema, minimizando a competição entre as espécies. O maior tamanho do folíolo de $P$. reticulata é compensado por outras características estruturais que denotam economia e reserva de água.

A cutinização da parede das células epidérmicas, detectada por meio de teste de coloração, permite perceber variações na intensidade do processo e a cutinização mais intensa em $P$. reticulata pode representar adaptação ao ambiente, assim como a espessura da parede.

A falta de significância na diferença da espessura da parede periclinal externa da epiderme adaxial e do bordo pode ser compensada pela intensidade da cutinização.

A posição dos estômatos em relação às demais células epidérmicas revela consonância com o ambiente das duas espécies, embora não haja diferença marcante neste posicionamento.
Nos feixes do mesofilo de $P$. reticulata, o maior número de células que compõe a extensão de bainha para o lado abaxial sugere translocação mais efetiva de solutos para a epiderme.

Mesofilo mais compactado, parênquima paliçadico em duas camadas com células mais altas são particularidades anatômicas da espécie do cerrado que, somadas às demais, manifestam a influência do ambiente e estabelecem características diferenciais entre as duas espécies.

Vários autores consideram os maciços de natureza esclerenquimática ou colênquimática na margem de folhas e folíolos como sendo característicos da vegetação xerofítica. Embora as espécies estudadas não pareçam ser xerofíticas, a maior quantidade de colênquima no bordo do folíolo de $P$. reticulata está em concordância com as demais particularidades apresentadas para esta espécie.

A consistência mais rígida dos tecidos em $P$. reticulata, resultante da presença de maior quantidade de fibras, confirma o escleromorfismo, considerado sob o ponto de vista anatômico, como característica estrutural marcante das plantas do cerrado (Paviani 1978). O termo escleromorfismo foi proposto por Arens (1958a, b) para as plantas do cerrado em substituição às características consideradas xeromórficas relacionadas com o suprimento de água. De acordo com Arens (1958a), escleromorfismo oligotrófico é causado por deficiências nutricionais do solo.

A redissolução dos cristais e a correlata lignificação das paredes das células que os contêm foram observadas no lenho de espécies do gênero Aspidosperma (Milanez 1937) e, posteriormente, no feloderma do caule de Cryptostegia grandiflora (Milanez 1966). Processo semelhante foi visto na folha de Annona pygmaea Warm. (Paviani \& Cavalcanti 1977$)$ e no pulvino de $P$. reticulata (Paviani \& Ferreira 1974).

Alexandrow \& Timofeev (1926 apud Franceschi \& Horner Jr. 1980) relatam a degradação de drusas e cristais prismáticos à semelhança do que ocorre com a degradação de grãos de amilo. Em Ricinus, cristais em drusa presentes no caule, inflorescência e eixo do fruto são degradados e substituídos por grãos de amilo (Scott 1941 apud Franceschi \& Horner Jr. 1980). Durante o desenvolvimento da folha de Virginia creeper, os cristais presentes no caule começam a desaparecer (Calmés 1969 apud 


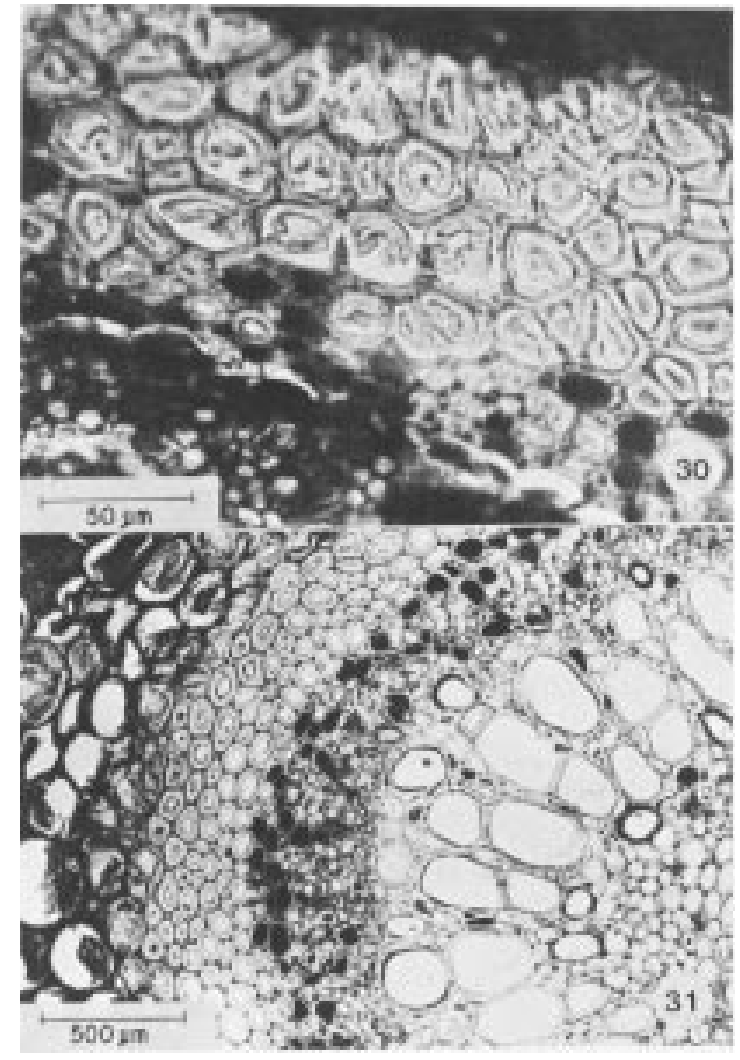

Figuras 30-31. Cortes transversais da raque e do peciólulo. Fibras gelatinosas na região perivascular. 30. Raque de Plathymenia reticulata; 31. Peciólulo de P. foliolosa.

Franceschi \& Horner Jr. 1980) e, segundo Calmés \& Carlos (1970 apud Franceschi \& Horner Jr. 1980), as ráfides desaparecem possivelmente como resultado da deficiência localizada de cálcio, causada pelo rápido crescimento das gemas (Calmés \& Piquemal 1977 apud Franceschi \& Horner Jr. 1980); desta forma o cristal agiria como fonte reparadora de cálcio. Poder-se-ia, então, pensar em estrutura de reserva, pelo menos temporária.

Pelo exposto, pode-se admitir a degradação dos cristais com consequiências diferentes: degradação com esclerose da parede celular evoca fases finais da diferenciação celular, possivelmente o início da morte do conteúdo celular; degradação e substituição por grãos de amilo sugere metabolismo celular ativo.

Stevenson (1953 apud Franceschi \& Horner Jr. 1980) propôs que os cristais de oxalato de cálcio, antes de ser produtos de excreção, podem estar relacionados com o metabolismo do nitrogênio. A função de proteção contra animais predadores, embora válida, talvez não seja a mais importante.

Considerando como secundária a condição de excreção e de produto do catabolismo e dadas as evidências da degradação, os cristais poderiam ser considerados como estruturas capazes de participar do metabolismo secundário das plantas. Assim sendo, a presença dos cristais estaria mais ligada a um processo fisiológico do que a influências do ambiente, embora não se possa negar a importância da composição química do solo na formação dos mesmos. $P$. reticulata, planta do cerrado, habitat que se caracteriza por um solo geralmente pobre, teria menos condições para "armazenar" cristais de oxalato de cálcio do que $P$. foliolosa, da mata, onde o solo é mais rico.

Metcalfe \& Chalk (1950) referem a presença de fibras gelatinosas no periciclo do caule de $P$. reticulata. A citação desses autores e a presença de fibras gelatinosas no lado adaxial do pecíolo, peciólulo e raque de $P$. foliolosa e $P$. reticulata sugerem uma possível relação com o lenho de tensão, uma vez que as fibras gelatinosas do xilema, em $P$. reticulata, são marcantes no lado adaxial (Paviani $\&$ Ferreira 1974), o que é visto também em $P$. foliolosa e, no lado adaxial do pecíolo de $P$. reticulata, o xilema apresenta menor número de elementos de vaso (Paviani 1974), característica também citada para o lenho de tensão (Beiguelman 1962, Scurfield \& Wardrop 1962).

Comparada à $P$. foliolosa, $P$. reticulata possui maior quantidade de fibras gelatinosas e a camada gelatinosa se apresenta mais espessa, tanto na região perivascular como no xilema. Associadas ou não ao lenho de tensão, é provável que as fibras gelatinosas sejam freqüentes nas plantas do cerrado e atuem como estruturas armazenadoras de água (Paviani 1974).

Baixa freqüência relativa de extensões de bainha e alta freqüência de estômatos são citados por Esau (1977) como particularidades relacionadas com o suprimento de água. Estas condições não ocorrem em $P$. reticulata e $P$. foliolosa possui maior número de estômatos (tabela 3). Já foi referido que as espécies em questão não são xerofíticas; mesmo assim é pertinente comentar a fragilidade das características xeromórficas citadas na literatura, sobretudo na estrangeira, e a impropriedade de 
generalizá-las para as plantas dos cerrados brasileiros.

No mesofilo de $P$. reticulata, Paviani \& Ferreira (1974) observaram degenerescência gomosa, com alterações estruturais do conteúdo e das paredes celulares; isto não foi visto em $P$. foliolosa. Mesmo considerando que os ataques bióticos ou mecânicos são esporádicos, é possível que $P$. reticulata, dadas às condições ambientais, seja mais vulnerável a esses ataques.

As particularidades morfo-anatômicas citadas para $P$. reticulata sugerem maior proteção às agressões do ambiente e mostram adaptações para economizar e armazenar água, garantindo o equilíbrio do balanço hídrico e permitindo a brotação da espécie em plena estação seca. Em condições ambientais mais favoráveis, $P$. foliolosa desenvolveu aspectos estruturais menos marcantes e menos perceptíveis e, as duas espécies, cada uma ao seu modo, estão perfeitamente adaptadas ao habitat, o que se pode confirmar pela sobrevivência das mesmas.

Com relação às hipóteses formuladas no início, as diferenças na morfologia externa se manifestam sobretudo na textura e no tamanho dos folíolos. Anatomicamente, a mesma organização espacial dos tecidos garante as afinidades taxonômicas e as particularidades inerentes a cada uma marcam a influência do meio. Posição taxonômica e habitat se entrelaçam e desta dupla condição harmônica resulta o paralelismo e as características diferenciais destas espécies vicariantes.

Agradecimentos - Ao Prof. José Elias de Paula pela identificação do material botânico (BOT-UnB), ao Prof. Nagib M. A. Nassar, do Lab. de Citogenética (EAG-UnB), por ter cedido o uso do microscópio Zeiss-Axioscop com câmara clara e ao Sr. Eronildes C. do Nascimento pela confecção das lâminas.

\section{Referências bibliográficas}

ARENS, K. 1958a. Considerações sobre as causas do xeromorfismo foliar. Bolm Fac. Filos. Ciênc. e Letr. Univ. S. Paulo (Bot.) 15:25-56.
ARENS, K. 1958b. O cerrado como vegetação oligotrófica. Bolm Fac. Filos. Ciênc. e Letr. Univ. S. Paulo (Bot.) 15:59-77.

BEIGUELMAN, B. 1962. Lenho de tensão (tension wood) em duas espécies vegetais frequientes nos Cerrados Brasileiros. An. Acad. brasil. Ciênc. 34:295-305.

ESAU, K. 1977. Anatomy of seed plants. John Wiley and Sons, New York.

FOSTER, A.S. 1949. Practical plant anatomy. D. Van Nostrand Company Inc., New York.

FRANCESCHI, V.R. \& HORNER Jr., H. T. 1980. Calcium oxalate crystals in plants. Bot. Rev. 46:361-427.

JOHANSEN, D.A. 1940. Plant microtechnique. McGrawHill Book Company, New York.

METCALFE, C.R. \& CHALK, L. 1950. Anatomy of the Dicotyledons. Vol. I. Clarendon Press, Oxford..

MILANEZ, F.R. 1937. Anatomia do lenho de Aspidosperma aquaticum Ducke. Arq. Inst. Biol. Vegetal (Rio de Janeiro) 4:65.

MILANEZ, F.R.1966. Contribuição ao conhecimento anatômico de Crypostegia grandiflora - III. Nota sobre a estrutura secundária. Rodriguésia 37:335-340.

PAULA, J.E. 1971. Anatomia de Catostemma albuquerquei Paula, Catostemma milanezzi Paula, Catostemma sclerophyllum Ducke e Scleronema micranthum (Ducke) Ducke - Bombacaceae da Amazônia. Tese de doutorado, Universidade Estadual de Campinas, Campinas.

PAVIANI, T.I. 1974. Sobre a ocorrência de fibras gelatinosas em Plathymenia reticulata Benth. Ci. e Cult. 26:783786.

PAVIANI, T.I. 1978. Anatomia vegetal e cerrado. Ci. e Cult 30:1076-1086

PAVIANI, T.I. \& FERREIRA, M.L. 1974. Anatomia foliar de Plathymenia reticulata Benth. Revta. brasil. Biol. 34:159-176.

PAVIANI, T.I. \& CAVALCANTI, R.B. 1977. Anatomia foliar de Annona pygmaea Warm. Trabalhos do XXVI Congresso nacional de botânica, Academia Brasileira de Ciências, Rio de Janeiro: 475-492.

RIZZINI, C. T. 1971. A flora do cerrado. Análise florística das savanas centrais. In Simpósio sobre o cerrado. Ed. Edgard Blücher, São Paulo, p.105-153.

SASS, J. E. 1958. Botanical microtechnique. The Iowa State College Press, Iowa.

SCURFIELD, G. \& WARDROP, A.B. 1962. The nature of reaction wood. Vl. The reaction anatomy of seedlings of woody perennials. Aust. J. Bot. 10:93-105.

WASICKY, R. 1959. Estudo farmacognóstico da folha de Psidum catleyanum Sabine. Tese de livre-docência, Universidade de São Paulo, São Paulo. 